\title{
From sense-making to perceived organizational performance: looking for the best way
}

\begin{abstract}
Purpose - Mission statements are a frequent strategic tool, yet little is known about their effects on economic performance. The main objectives of this study are to model and to assess the relationships between sense-making of the mission statement (SM), employee mission engagement (EME), organizational mission fulfillment (OMF) and performance (PER), and a secondary objective is to determine the path that better explains these linkages.

Design/methodology/approach - This article reports the results of an empirical investigation drawn from a sample of 132 managers at different levels in two Spanish companies. The data analysis was performed in two steps: the first was to assess the reliability of the measurement scales; the second was to build the causal model using structural equation modeling (SEM) analysis.

Findings - The finding suggests that the best path to explain the relationships between the mission statement and performance are $\mathrm{SM} \rightarrow \mathrm{EME} \rightarrow \mathrm{OMF} \rightarrow \mathrm{PER}$, with a full mediation effect of EME and OMF. These findings are consistent with previous research.

Practical implications - The managerial implications of these results are discussed. Just having a good mission and effective communication of the mission is not enough. The mission has to be related to employee's engagement and to be a mission-driven organization.

Originality/value - This research provides a new paradigm for understanding the relationships between sense-making around the mission statement (SM), employees' mission engagement (EME), organizational mission fulfillment (EME), and perceived organizational performance (PER), and it helps to adjudicate among possible outcome paths and better explain the inter-relationships between these constructs.
\end{abstract}

Keywords - Sense-making of the mission statement, Employee mission engagement, Organizational mission fulfillment.

Paper type - Research paper 


\section{Introduction}

A mission statement is a declaration of an organization's reason for being that reveals what the organization wants to be and whom it wants to serve (David, 1989; Noy, 1998; Abrahams, 1999; Bart et al., 2001). Mission statements are potentially an invaluable tool for formulating and implementing an organization's strategy (Baetz and Bart, 1996; Mullane, 2002; Lin, 2012), as they are regarded as the critical starting point of any strategic initiative and are considered de rigueur in initiating most modern management practices (Bart, 2001). However, a mission statement is more than a strategic tool (Pearce, 1982) because it can serve as a guide for decision-making, give meaning to work that engages and motivates employees, and enable and instill coherence within the organization by providing directions and clear goals (Bart, 2001; Desmidt et al., 2011).

Although for some the value of mission statements has yet to be demonstrated (Grundy, 1995), a degree of consensus exists within literature regarding their relevance and importance (Drucker, 1954, Hamel, 1996, Williams et al., 2014). According to Desmidt et al. (2011), for the past twenty years the performance implications of mission statements have been important avenues for research. Marimon et al., (2016) analyzed the employees' internalization of the mission and how this internalization is composed by five dimensions. However, the impacts of mission statements on performance are still unclear. For example, Bart et al., (2001) supports the idea that mission statements affect the organization's financial success. Green and Medlin (2003) and Bartkus et al. (2006) proposed a scale to measure the quality of a mission statement to assess its relationship with financial performance, showing a positive and significant relationship. Other researchers have also suggested evidence for a positive relationship between mission statements and performance (such as Hirota et al., 2010, Desmidt et al., 2011 and Babnik et al., 2014 among others). On the contrary, O'Gorman and Doran (1999) suggest that mission statements per se are not correlated positively with SME performance (see also other studies such as Atrill et al., 2005; Bart and Baetz, 1998; Baetz and Kenneth, 1998; or Dharmadasa et al., 2012). In short, the empirical literature suggests that there is a modest positive relationship between mission statement quality and financial measures (Desmidt et al., 2011). In this sense, this lack of consistent results could provoke to managers into a loss of trust in mission statements as an effective strategic tool 
(Sidhu, 2003). For this reason, further research into the relationships between these two constructs must be conducted to shed light on the relative effectiveness of mission statements in general.

Accordingly, the main objectives of this study are to model and to assess the relationships between sense-making of the mission statement, employee mission engagement, organizational mission fulfillment and performance, and a secondary objective is to determine the path that better explains these linkages. The results of this study provide a new framework for understanding the relationships between mission statements and perceived organizational performance, with considerations of the mediating effects of employee mission engagement and organizational mission fulfillment. More research is needed to propose a conclusive link between these two constructs (mission statements and performance), which are of key interest to service researchers and managers (Sidhu, 2003). Additionally, only a small number of studies have examined mediating effects (Braun et al., 2012) as proposed in our model. Hopefully, our research will contribute to a better understanding of the pathway from the definition and understanding of the mission statement to its impact on perceived organizational performance.

The paper is organized as follows: the next section presents the background and the hypotheses; then, the methodology is described and results from the analysis are presented. Finally, the discussion and contributions of the paper are explained.

\section{Background and hypothesis}

According to Wang (2011) the sense-making of the management philosophy is 'the process through which individuals develop cognitive maps of the management philosophy'. Therefore, the sense-making of the mission is related to the process through which individuals understand the mission of the company. This sense-making of the mission is especially relevant because normally the philosophy and the mission are abstract concepts, and employees do not know how to act in accordance with these concepts. Thus, the sensemaking of the mission is the first step to really knowing how to put the mission into practice to achieve the company's purpose (Wang, 2011).

To expand the mission statement and to encourage internalization and commitment toward the mission statement, employees must have explicit knowledge of the mission's content 
(Nonaka, 1994). Additionally, it is relevant to managers consider the extent to which employees are able to explain the mission in their own words (Wang, 2011). In fact, although implicit or tacit knowledge of the mission is an option (Nonaka and Tokoyama, 2003), several studies demonstrate the importance of the mission being formally communicated by members of the organization (Hirota et al., 2010), with special attention paid to the denotative and connotative aspects of the message (Cochran et al., 2008). The denotative aspect refers to the correct interpretation of the meaning of the message, and the connotative aspect refers to feelings and emotions that emerge in the process of its transmission. This last aspect is relevant to enhancing employees' motivations and commitment to the mission.

Employee engagement refers to individuals' involvement and satisfaction with the company, as well as their enthusiasm for work (Harter et al., 2002). According to Maslach and Leiter (2008), engagement is related to involvement, energy, and efficacy, the direct opposites of burnout. In the academic literature, engagement is said to be related to - but distinct fromother constructs in organizational behavior, such as organizational commitment or job involvement. According to Saks (2006), we can consider employee engagement, "a unique construct that consists of cognitive, emotional, and behavioral components that are associated with individual role performance". In the mission literature, following Suh et al., (2011), employee mission engagement (hereafter, EME) can be defined as 'a psychological state in which an employee desires to exert effort and devote careful attention to ensure the fulfillment of a mission that he or she perceives as significant or meaningful'.

The connotative aspects of the mission communication influence employee behaviors and feelings. For this reason, the knowledge and understanding of the mission that employees show, in terms of explaining it in their own words, is an antecedent to ensuring employees' engagement with the mission. The understanding of the mission is the first step to employees being truly involved and working towards the mission (Kim and Lee, 2007). Mission statements are acknowledged as an efficient tool that can motivate and engage employees and keep them dedicated and devoted to the firm's goals (Brown and Yoshioka, 2003). Hence, we propose that (see Figure 1):

$H_{1}$ : Sense-making of the mission is positively related to employee mission engagement (EME). 
Previous research has highlighted the motivational nature of the concept of EME (Saks, 2006). Employee motivation is one of the main reasons to define a mission statement (Bart et al., 2001; Ireland and Hitt, 1992; Campbell \& Yeung, 1991; Klemm et al., 1991). Previous studies have proposed a relationship between employee motivation and mission statements, for instance in the public sector (Wright 2007) and in non-profit organizations (Kirk, 2010). Hirota et al. (2010) suggested that one of the functions of mission statements is to encourage employees' efforts and actions through clearly stated sets of strategic-value priorities (motivational function). Mission statements can motivate and inspire employees, affecting employee behaviors as they pursue a common purpose (Germain and Cooper, 1990; Collins and Porras, 1996; Klemm et al., 1991; Daniel, 1992; Wilson, 1992; Campbell, 1993; among others).

EME is an essential key to success (Hamel, 1996). Mission statements can be a facilitator in accomplishing this commitment, generating a sense of mission in the company and encouraging employees to attach both rationally and emotionally with the organization's purpose (Campbell and Yeung, 1991). People feel a necessity to exceed their day-to-day work and to have a positive impact on others (Grant et al., 2007, Grant, 2008), and managers must learn to use this potential, reinforcing the fulfillment of a common mission (Wang, 2011).

Central to the motivational nature of EME is the notion of an employee's willingness to invest personal effort and attention into fulfilling the mission (Salanova et al., 2005). Employees with high EME tend to commit to and to continue to work towards the firm's goals. According to Suh et al. (2011), employee engagement is necessary to be a mission-driven organization wherein the mission is fulfilled in its processes, products and services. It might be said that EME has become an essential dimension for a mission-driven organization. According to Bart (2001), one of the keys to mission fulfillment is the degree to which employees are committed and engaged with their organization's mission. Based on previous research and experience, the following hypothesis can be made (see Figure 1):

$H_{2}$ : Employee mission engagement is positively related to organizational mission fulfillment. 
Drucker $(1974,1990)$ indicates that superior performance should be related to a mission statement that emphasis organizational tasks and processes. As we have commented before, some researchers propose a direct pathway between mission statements and performance, and the findings are diverse. Bart and Hupfer (2004) suggest a relationship between mission statement content and perceived performance in Canadian nonprofit hospitals. Similarly, Weiss \& Piderit (1999) found a limited linkage between mission statement content and performance in K-12 schools. Sidhu (2003) suggested that a mission statement could lead to superior performance. Moreover, Williams et al. (2014) suggested a positive relationship between the extent that a mission statement is complete (including vision, business domain, competencies and values) and firm performance. Some studies have found a positive relationship between mission statements and desired organizational behaviors (Bart, 1997; Bart et al., 2001, Mullane, 2002; Desmidt et al., 2011, among others). By contrast, Bart \& Baetz (1998) did not find that the simple presence of a mission statement affected a firm's performance significantly (see also Atrill et al, 2005; Green and Medlin or O'Gorman and Doran, 1999, among others).

We can provide some potential explanations for these inconclusive results. Khalifa (2011) suggested that these inconsistencies stem from considerations of the concept of 'mission'. Thus, Khalifa (2011) request more precision and clarity in what is defined as a 'mission' statement. Additionally, Williams et al., (2014) suggest that mission statements are a good strategic tool if the top management is willing to make the commitment to use them. In many companies, because it is hard and challenging work, the mission was not being implemented in the correct manner, and its impact on performance was weak or nonexistent.

Organizational mission fulfillment (hereafter, OMF), also called mission-driven organizations (Wang, 2011), are ones in which the organization's behaviors fit their mission statements, which they formally define as "the state in which an organization consistently acts (publicly and privately) in a manner that is congruent with and leads to the fulfillment of its corporate mission statement, that is, its fidelity to, versus violation of, its professed mission." Many companies have a mission statement, but only a few of them manage their day-to-day processes and operations in line with this mission statement. The use of mission statements as a strategic tool can help managers to enhance their performance (Mullane, 
2002). Organizations in which managers and employees work towards their mission statements derive direct and indirect benefits on economic outcomes (Bart and Hupfer, 2004; Sidhu, 2003; Bart et al., 2001, among others). Based on the foregoing, we suggest that (see Figure 1):

$H_{3}:$ Organizational mission fulfillment is positively related to performance.

We have stated before that the sense-making of the mission is connected to the process through which individuals understand the mission of the company. This personal process to know and understand the sense of the company's mission can be considered a necessary antecedent to achieving fulfillment and implementation within the organization. A truly mission-fulfilled organization is an entity in which the managers and workers keep the mission in mind as a guide for their decisions.

According to many previous studies (Desmidt et al., 2011), common benefits generated within a company after the adoption of a mission statement include the following: (i) providing an accurate and comprehensible purpose for the company (Bart et al., 2001); (ii) acting as a strategic framework for allocating organizational resources (Bartkus et al., 2000); (iii) facilitating communications with internal and external stakeholders (Bartkus et al., 2008); and finally, (iv) acting as a cultural control an coordinating mechanism that emphasizes to employees the fulfillment of strategic goals (Campbell \& Yeung, 1991). In this sense, as has been shown by previous studies, the sense-making of the mission should enhance how companies are managed by missions and achieve organizational mission fulfillment. According to Bart (2001), one of the most important aspects of mission fulfillment seems to be the degree to which employees know and understand their organization's mission. Hence, we propose the following:

$H_{4}$ : Sense-making of the mission is positively related to organizational mission fulfillment.

There has been a stream of research focused on individual attitudes towards mission statements and their impacts on organizational outcomes such as performance. This research has typically been based on the idea that positives attitudes of employees towards the organization's mission statement are positively linked to mission statement effectiveness 
(Bart, 2001; Bart et al., 2001; Brown and Yoshioka, 2003; Kim and Lee, 2007; Urbany, 2005, among others). According to Braun et al. (2012), mission commitment and attachment are positively related to desired organizational outcomes. On the contrary, negative employee attitudes towards the mission statement are negatively linked to organizational performance (Urbany, 2005). According to Kim and Lee (2007), nonprofit organizations have been considered mission-driven organizations, in which people are involved by their passion for the mission and continue in the organization to achieve it. Consequently, this drive affects career advancement and turnover intention, with a positive impact on the bottom-line. We hope to model similar behaviors in for-profit companies. Thus, it is desirable in a missiondriven company to find employees working hard to ensure the fulfillment of a mission. Hence, we propose the following (see Figure 1):

\section{$H_{5}:$ Employee mission engagement is positively related to performance.}

As we have stated before, several empirical studies have found a positive relationship between mission statements and organizational performance (such as Green and Medlin, 2003; Sidhu, 2003; Hirota et al., 2010). However, previous researchers have also suggested a convoluted or inconclusive association between knowledge of the mission statement and performance (Braun et al., 2012). We consider that the understanding of an effective mission statement might affect perceived organizational performance. Based on previous studies cited in the justification of $\mathrm{H}_{3}$, our next hypothesis can be made:

$H_{6}:$ Sense-making of the mission is positively related to performance.

To sum up, we suggest the following research model with the hypotheses proposed in Figure 1:

Please, insert Figure 1 about here

\section{Methodology}

\subsection{Sample}


A series of meetings with managers from two companies was conducted to explain the aims of this study. The first company is a market leader in spare auto parts distribution that was established in Spain and operates across Europe. The second company operates internationally in engineering construction activities, and its headquarters are located in South America. Five managers agreed to participate in the development of the questionnaire. Before the questionnaire was launched, some pilot managers completed it and suggested some changes to enhance understanding. Managing directors at different levels within the two target companies were targeted as respondents. According to Sidhu (2003), managing directors or business unit managers are normally seen as the most competent individuals to provide suitable answers to questions related to organization-level issues.

The questionnaire included one section of 11 items assessing the constructs explained above. These items were based on previous quantitative studies in the mission statement literature. In the second section, the respondents' socio-demographic information was collected.

The survey was launched in January 2015, and 156 questionnaires were collected, from which only 132 were retained for our analysis (61 from the first company and 71 from the second company). All of the items were presented as statements to which respondents indicated their agreement/disagreement on a five-point Likert-type scale (from $1=$ strongly disagree to $5=$ strongly agree). The data was analysed using Structural Equation Modelling (SEM) with SPSS and EQS 6.2.

\title{
3.2. Measures
}

Table 1 show the scales of the constructs used in our study based on previously validated scales.

\author{
Please, insert Table 1 about here
}

\section{Results}

The data analysis was performed in two steps: the first was to assess the reliability of the measurement scales; the second was to build the causal model using structural equation modeling (SEM) analysis. 


\subsection{Measurement scale reliability}

The preliminary study of the scales' dimensionality was conducted using an array of exploratory principal components factor analyses with a Varimax rotation (Hair et al., 2010), using the Kaiser criteria of eigenvalues greater than 1 (see Table 2). Next, the psychometric properties of the scales of measurement were analyzed.

Please, insert Table 2 about here

In each one of the four analyses, only one factor was extracted, proving unidimensionality. All the loads were above 0.7 . All of the Cronbach's alphas were also above the 0.7 threshold. The composite reliability indices and AVE also accounted for the internal consistency and reliability of the four constructs.

Discriminant validity, which verifies that each factor represents a separate dimension, was analyzed through linear correlations or standardized covariances between latent factors by examining whether inter-factor correlations were less than the square root of the average variance extracted (AVE) (Fornell and Larcker, 1981). Table 3 shows that the square roots of each AVE were greater than the off-diagonal elements.

Please, insert Table 3 about here

\subsection{Structural equation model}

In accordance with the theoretical framework as analyzed, the model where all the intermediate paths are considered is presented in figure 1.

The model was estimated with the robust maximum likelihood method from the asymptotic variance-covariance matrix (Jöreskog and Sörbom, 1996). To assess data fitness the following indices were calculated: the $\chi^{2}$ Satorra-Bentler was 153.12, with 84 degrees of freedom and a p-value of $0.00001 ; \chi^{2} / \mathrm{df}$ was 1.82 , which was lower than the acceptance limit of 5 (Hair et al., 2010); the RMSEA was 0.079; the CFI was 0.898 and the BB-NNFI was 0.873 (Byrne, 2013, Hu and Bentler, 1999). Taking into account the significance of the robust $\chi^{2}$ statistic and observing the global indicators, we can state that the global fit was on the very edge of acceptance. 
Table 4 shows the structural results. All direct paths from each construct to the next one in the sequence SM-EME-OMF-PER were confirmed to be significant. On the other hand, none of the remaining paths within the model were significant. The $\mathrm{r} 2$ for the dependent constructs were 0.207 for EME, 0.432 for OMF and 0.230 for PER.

Please, insert Table 4 about here

Following these results, we dropped the non-significant paths, resulting in a new model (figure 2) wherein each construct was only explained by the previous construct. The fit indices were slightly better than in the previous model: $\chi^{2}$ Satorra-Bentler was 153.96, with 89 degrees of freedom and a p-value of $0.00001 ; \chi^{2} / \mathrm{df}$ was 1.87 , which was lower than the acceptance limit of 5 (Hair et al., 2010); the RMSEA was 0.077; the CFI was 0.901; and the BB-NNFI was 0.881 .

Please, insert Figure 2 about here

To compare fitness between the general model proposed, where all the mediation paths were considered (figure 1), and the new, more restricted model where only the direct links between the four constructs are considered (figure 2), the Wald test was conducted. This test suggests that if the mediation parameters specified in the general model could be set to zero without substantial loss in the model fit in the original model, than the modification is appropriate. Table 5 shows that the three parameters that provides direct paths in the model can be removed.

Please, insert Table 5 about here

To test if the degradation expected on the Satorra-Bentler chi-square after removing the three parameters was significant, the corrected computation was performed (Satorra, Bentler, 2001). The $\Delta \mathrm{S}-\mathrm{B} \chi^{2} 1.046$ (with an increment of freedom degrees of three) was nonsignificant, arguing for the redundancy of the three parameters suggested and, hence, proving the best fit of the restricted model to be the model that only considered the three paths among the four constructs. 
Our results confirm that EME and OMF are mediating the effects of SM on PER in the pathway shown in figure 2 . Table 3 shows the results. The $r^{2}$ for the dependent constructs were 0.212 for EME, 0.443 for OMF and 0.320 for PER.

Please, insert Table 6 about here

\section{Discussion and practical implications}

The present study confirms that the best pathway for explaining the relationship between mission statements and performance is from sense-making of the mission $\rightarrow$ employee mission engagement $\rightarrow$ organizational mission fulfillment and perceived organizational performance $(\mathrm{SM} \rightarrow \mathrm{EME} \rightarrow \mathrm{MF} \rightarrow \mathrm{PER})$. Moreover, EME and OMF fully mediated the relationship between sense-making of the mission statement and perceived organizational performance.

In other words, there is not a shortcut to get real results; there is a long way from the employees' sense of mission to tangible results. Hence, two main lessons can be learnt: (i) the way that ends on performance results starts on the accuracy in mission definition and in the involvement employees in its definition (consistent to findings of Wang (2011) and Nonaka (1994)), and (ii) there are other two stations that are needed to reach in the way to performance (see also Saks, 2006 and Druker, 1990).

Consequently, it is completely compulsory to guarantee the three first steps are achieved and to be sure that none of them are neglected. This is the symmetrical reading of the previous two lessons: if EME or MF are not well established, the performance results will never come. The entire chain must be accomplished.

This sequence in achieving all these constructs also implies that (i) the continuous improving effort to achieve all the constructs needs to be established as a long term program; (ii) the available resources to implement first three constructs need to be allocated harmoniously and in a balanced way; (iii) the performance achievement guarantees the future resources to reinforce the three first constructs, providing to the system a cyclic view; and (iv) monitoring the first three constructs is needed in order to assure that there is a consistency with the expected results along time. 
The results of this research have important implications for managers and practitioners. When designing the mission statement, some strategies should be implemented to make an impact on organizational performance. First, the sense-making of the mission, per se, is not affecting the organizational outcomes. Although a company may define a very attractive and original mission statement, the presence of the mission statement alone is not enough to ensure success or to affect perceived organizational performance. Ensuring broad understanding of the meaning of the mission is the first step towards employees working towards a common purpose. According to Williams et al. (2014), it is important and relevant to clearly communicate the mission to employees. Second, motivated and engaged employees around the organizational mission do not alone impact performance. EME is a necessary antecedent to be an OMF, which means to be a mission-driven organization. Mission-driven organizations often attract employees with high levels of motivation that goes beyond their own singular interests (Wang, 2011). A collective purpose drives companies towards their goals and engenders the enthusiasm of their employees (Bart, 2001). Finally, an OMF positively affects upon perceived organizational performance. That is, a mission truly internalized by employees and with full alignment between mission and processes (Crotts et al., 2005) affects perceived organizational performance.

Many companies may spend significant time and money designing and implementing mission statements. Thus, it is relevant to ask the following question: are mission statements useful? Overall, our study suggests that the pathway from sense-making of the mission, employee mission engagement, organizational mission fulfillment and, finally, perceived organizational performance is the most effective and consistent one.

There has been a lack of conclusive evidence for the relationships between mission statements and performance, and future research is needed in this vein. Immediate future steps include replicating the results of this study using a larger sample and a more diverse (in different industries or types of companies) sample to generalize these results.

\section{Conclusions}


This research proposes a model of the relationship between sense-making of the mission statement by the employees and perceived organizational performance. This research field is especially valuable due to a lack of consensus around the applications of mission statements to firm performance. Our model shows the full mediation of employee mission engagement as well as organizational mission fulfillment of the understanding of the mission and perceived firm performance.

Just having a good mission and effective communication of the mission is not enough. The mission has to be deployed "on the ground", in other words, in driving employees' behaviors in ways that will yield increases in performance indicators. To make mission statements work effectively, two other constructs have to cooperate with and enable them. The first mediator is the extent to which the employees are engaged with the mission, and the second is the fulfillment of the mission during day-to-day routines. These two constructs make it possible for the mission to lead to real benefits.

We believe that these findings should strengthen the discussion of the role of mission statements and their implications for employees and organizations. Much more research is required in this area to achieve optimal effectiveness in mission-driven organizations. 


\section{References}

Abrahams, J. (1999), The mission statement book: 301 corporate mission statements from America's top companies. Ten Speed Press, Berkeley, CA.

Atrill, P., Omran, M. and Pointon, J. (2005), "Company mission statements and financial performance”, Corporate Ownership and Control, Vol. 2 No. 3, pp. 28-35.

Babnik, K., Breznik, K., Dermol, V., \& Trunk Širca, N. (2014). The mission statement: organisational culture perspective. Industrial Management \& Data Systems, 114(4), 612-627.

Baetz, M. C. and Bart, C. K. (1996), "Developing mission statements which work", Long Range Planning, Vol. 29 No. 4, pp. 526-533.

Baetz, B. and Kenneth, C. (1998), "The relationship between mission statements and firm performance: An exploratory study”, Journal of Management Studies, Vol. 35 No. 6, pp. 823-853.

Bart, C. (1997), “Sex, lies and mission statements”, Business Horizons, Vol. 40, No. 6, pp. 9-18.

Bart, C. K. (2001), "Measuring the mission effect in human intellectual capital", Journal of Intellectual Capital, Vol. 2 No. 3, pp. 320-330.

Bart, C. and Baetz. M. (1998), "The relationship between mission statements and firm performance: an exploratory study", Journal of Management Studies, Vol. 35 No.6, pp. 823853.

Bart, C. K., Bontis, N. and Taggar, S. (2001), "A model of the impact of mission statements on firm performance”, Management Decision, Vol. 39 No. 1, pp. 19-35.

Bart, C. K. and Hupfer, M. (2004), "Mission statements in Canadian hospitals", Journal of Health Organization and Management, Vol. 18 No. 2, pp.92-110.

Bartkus, B. R. and Glassman, M. (2008), "Do firms practice what they preach? The relationship between mission statements and stakeholder management", Journal of Business Ethics, Vol. 83 No. 2, pp. 207-216.

Brown, W. A. and Yoshioka, C. F. (2003), "Mission attachment and satisfaction as factors in employee retention”, Nonprofit Management and Leadership, Vol. 14 No. 1, pp. 5-18.

Byrne, B. M. (2013), Structural equation modeling with EQS: Basic concepts, applications, and programming. Routledge. 
Braun, S., Wesche, J. S., Frey, D., Weisweiler, S. and Peus, C. (2012), "Effectiveness of mission statements in organizations-A review", Journal of Management \& Organization, Vol. 18, pp. 430-444.

Campbell, A. (1993), "The power of mission: Aligning strategy and culture", Planning Review, Special Issue.

Campbell, A. and Yeung, S. (1991), "Creating a sense of mission”, Long Range Planning, Vol. 24 No. 4, pp. 10-20.

Cochran, D. S., David, F. R. and Gibson, C. K. (2008), "A framework for developing an effective mission statement”, Journal of Business strategies, Vol. 25 No. 2, pp.27.

Collins, J. C. and Porras, J. I. (1996), "Building your company's vision”, Harvard Business Review, Vol. 74 No. 5, pp. 65.

Crotts, J. C., Dickson, D. R. and Ford, R. C. (2005), “Aligning organizational processes with mission: the case of service excellence", The Academy of Management Executive, Vol 19, No. 3, pp. 54-68.

Daniel, A. L. (1992), "Strategic planning - the role of the chief executive", Long Range Planning, Vol. 25 No. 2, pp. 97-104.

Dharmadasa, P., Maduraapeurma, Y. and Herath, S. K. (2012), "Mission statements and company financial performance revisited", International Journal of Managerial and Financial Accounting, Vol. 4 No. 3, pp. 314-324.

David, F. R. (1989), "How companies define their mission”, Long Range Planning, Vol. 22 No. 1, pp. 90-97.

Desmidt, S., Prinzie, A. and Decramer, A. (2011), "Looking for the value of mission statements: a meta-analysis of 20 years of research", Management Decision, Vol. 49 No. 3, pp. 468-483.

Drucker, P.F. (1954), “The Practice of Management, Harper”, New York, NY.

Drucker, Peter. (1954), "Management: Tasks, Responsibilities and Practices, Harper \& Row." New York, NY.

Drucker, P. F. (1990), “The emerging theory of manufacturing”, Harvard Business Review, 68(3), 94-102.

Fornell, C. and Larcker, D.F., (1981), "Evaluating structural equation models with unobservable variables and measurement error", Journal of Marketing Research, Vol. 281, pp. 39-50. 
Germain, R. and Cooper, M. B. (1990), "How a customer mission statement affects company performance”, Industrial Marketing Management, Vol. 19 No. 1, pp. 47-54.

Grant, A. M., Campbell, E. M., Chen, G., Cottone, K., Lapedis, D. and Lee, K. (2007), "Impact and the art of motivation maintenance: The effects of contact with beneficiaries on persistence behavior", Organizational Behavior and Human Decision Processes, Vol. 103 No. 1, pp. 53-67.

Grant, A. M. (2008), "Does intrinsic motivation fuel the prosocial fire? Motivational synergy in predicting persistence, performance, and productivity", Journal of Applied Psychology, Vol. 93 No. 1, pp. 48.

Green Jr, W. K. and Medlin, B. (2003), "The Strategic Planing Process: The Link Between Mission Statement and Organizational Performance", Academy of Strategic Management Journal, Vol. 24, pp.16.

Grundy, T. (1995), "Destroying shareholder value: Ten easy ways", Long Range Planning, Vol. 28, pp. 7-83.

Hair, J. F. J., Black, W. C., Babin, B. J. and Anderson, R. E. (2010), "Multivariate Data Analysis Seventh Edition Prentice Hall”.

Hamel, G. (1996), “Strategy as Revolution”, Harvard Business Review, July-August, pp. 6982.

Harter, J. K., Schmidt, F. L. and Hayes, T. L. (2002), "Business-unit-level relationship between employee satisfaction, employee engagement, and business outcomes: a metaanalysis". Journal of Applied Psychology, Vol. 87 No. 2, pp. 268.

Hirota, S., Kubo, K., Miyajima, H., Hong, P. and Won Park, Y. (2010), “Corporate mission, corporate policies and business outcomes: evidence from Japan”, Management Decision, Vol. 48 No. 7, pp. 1134-1153.

Ireland, R. D. and Hitt, M. A. (1992), "Mission statements: Importance, challenge, and recommendations for development”, Business Horizons, Vol. 35 No. 3, pp. 34-42

Kim, S. E. and Lee, J. W. (2007), "Is mission attachment an effective management tool for employee retention? An empirical analysis of a nonprofit human services agency", Review of Public Personnel Administration, Vol. 27 No. 3, pp. 227-248.

Jöreskog, K.G. and Sörbom, D. (1996), PRELIS 2 user's reference guide, Chicago: Scientific Software International 
Klemm, M., Sanderson, S. and Luffman, G. (1991), "Mission statements: selling corporate values to employees", Long Range Planning, Vol. 24 No. 3, pp. 73-78.

Marimon, F., Mas-Machuca, M., \& Rey, C. (2016). Assessing the internalization of the mission. Industrial Management \& Data Systems, 116(1), 170-187.

Maslach, C. and Leiter, M. P. (2008), "Early predictors of job burnout and engagement", Journal of Applied Psychology, Vol. 93 No. 3, pp. 498.

Mullane, J. V. (2002). "The mission statement is a strategic tool: when used properly". Management Decision, Vol. 40 No. 5, pp.448-455.

Nonaka, I. (1994), “A dynamic theory of organizational knowledge creation”. Organization Science, Vol. 5 No. 1, pp.14-37.

Nonaka, I. and Toyama, R. (2003), "The knowledge-creating theory revisited: knowledge creation as a synthesizing process", Knowledge Management Research \& Practice, Vol. 1 No. 1, pp. 2-10.

Noy, E. (1998). "Total business strategy—the missing link", Long Range Planning, Vol. 31 No. 6, pp. 927-932.

O'Gorman, C. and Doran, R. (1999), "Mission statements in small and medium-sized businesses", Journal of Small Business Management, Vol. 37 No. 4, pp. 59.

Pearce, J. A. (1982), “The company mission as a strategic tool”, Sloan Management Review, Vol. 23 No. 3, pp. 15-24.

Saks, A. M. (2006), "Antecedents and consequences of employee engagement", Journal of Managerial Psychology, Vol. 21 No. 7, pp. 600-619.

Salanova, M., Agut, S. and Peiro, J. M. (2005), "Linking organizational resources and work engagement to employee performance and customer loyalty: the mediation of service climate", Journal of Applied Psychology, Vol. 90 No. 6, pp. 1217.

Satorra, A. and Bentler, P. M. (2001), "A scaled difference chi-square test statistic for moment structure analysis”, Psychometrika, Vol. 66 No. 4, pp. 507-514.

Sidhu, J. (2003), “Mission Statements: Is it Time to Shelve Them?”, European Management Journal, Vol. 21, pp. 439-446.

Suh, T., Houston, M. B., Barney, S. M. and Kwon, I. W. G. (2011), "The impact of mission fulfillment on the internal audience: psychological job outcomes in a services setting", Journal of Service Research, Vol. 14 No. 1, pp. 76-92. 
Urbany, J. E. (2005), "Inspiration and cynicism in values statements", Journal of Business Ethics, Vol. 62 No. 2, pp. 169-182.

Wang, Y. (2011), "Mission-driven organizations in Japan: Management philosophy and individual outcomes", Journal of Business Ethics, Vol. 101 No. 1, pp. 111-126.

Williams Jr, R., L. Morrell, D. and V. Mullane, J. (2014), "Reinvigorating the mission statement through top management commitment", Management Decision, Vol. 52 No. 3, pp. 446-459.

Wilson, I. (1992), "Realizing the power of strategic vision”, Long Range Planning, Vol. 25 No. 5, pp. 18-28.

Wright, B. E. (2007), "Public service and motivation: does mission matter?", Public Administration Review, Vol. 67 No. 1, pp. 54-64. 